\title{
AC 2011-2482: ON THE IMPLEMENTATION OF ABET FEEDBACK FOR PROGRAM IMPROVEMENT
}

\section{Stephen M. Phillips, Arizona State University}

Stephen M. Phillips received the B.S. degree in electrical engineering from Cornell University and the M.S. and Ph.D. degrees in electrical engineering from Stanford University. He has served on the faculty of Case Western Reserve University from 1988 to 2002. He joined the faculty of Arizona State University in 2002 as Professor. In 2005 was appointed department chair and in 2009 he was appointed director of the newly formed School of Electrical, Computer and Energy Engineering.

\section{Konstantinos Tsakalis, Arizona State University}

Dr. Konstantinos Tsakalis is a Professor in the School of Electrical, Computer, and Energy Systems Engineering at Arizona State University since 1988. His work is in the theory and applications of control systems, adaptive control, system identification and optimization and he co-authored the book "Linear Time Varying Plants: Control and Adaptation," published by Prentice Hall in 1993. Starting in 1995 and in collaboration with Semy Engineering, he developed an integrated identification and controller design procedure for the temperature control of diffusion furnaces, used in semiconductor manufacturing. This controller was awarded 5 US patents received the 1998 Editor's Choice, Best Products Award from Semiconductor International. Dr. Tsakalis has also worked on the application of robust control theory, system identification and optimization principles in various industrial problems in collaboration with Honeywell and EPRI. His recent activities include power system and biomedical applications, and in particular, prediction and control of epileptic seizures. He is also actively pursuing the use of industrial research experience in the classroom, with support from several funded projects.

\section{Ravi Gorur, Arizona State University}

Ravi Gorur joined the faculty at Arizona State University in 1987 and he is presently professor and program chair of the electrical engineering undergraduate program. He has Bachelor's, Master's and Ph. $\mathrm{D}$ degrees in electrical engineering. His area of research is dielectric materials and systems for power delivery. He has authored or co-authored over 150 papers in journals and a textbook on "Outdoor Insulators". He teaches classes in the electric power and energy systems area. He is a Fellow of the IEEE and the recipient of the 2011 Claude de Tourreil Memorial Award for "Lifetime Achievement in the Field of Electrical Insulators".

\section{Stephen M Philips, Arizona State University}

Stephen M. Phillips received the B.S. degree in electrical engineering from Cornell University and the M.S. and Ph.D. degrees in electrical engineering from Stanford University. He has served on the faculty of Case Western Reserve University from 1988 to 2002. He joined the faculty of Arizona State University in 2002. In 2005 was appointed department chair and in 2009 he was appointed director of the newly formed School of Electrical, Computer and Energy Engineering. 


\title{
On the implementation of ABET feedback for program improvement
}

\begin{abstract}
The ABET accreditation process calls for feedback to be an integral part of continuous improvement of education programs. Considerable freedom is allowed in the implementation of this process and how the data is collected, quantified, and interpreted. Combining this with the naturally high variability of the education experience, the lack of unified and accepted performance metrics and outcome definitions, result in a formidable yet quite interesting feedback problem.
\end{abstract}

In this study, we present the approach taken for an EE program at a large state university to formalize, quantify, and automate to the greatest possible extent the data collection, action, and evaluation of the feedback and continuous improvement process. We follow the "two loop ABET process" where the academic unit defines its own program objectives that are continuously evaluated and possibly revised by the program constituents: faculty, students, alumni, local community and industry. The evaluation of how well the program objectives are met is accomplished through regular meetings and responses to questionnaires. We quantify these responses with an adjustment of the target values of the program outcomes. Despite the fact that it is naturally abstract and vague, and some nontrivial effort must be spent on the development of the questionnaires and their correspondence with the program outcomes, the implementation of this loop is relatively straightforward.

The second, and arguably more interesting part of the cycle is the assessment and evaluation of the program outcomes, and the implementation of actions and policies to affect the outcomes in a desired direction. We approach this by creating a sampling mechanism through standardized tests and questionnaires (rubrics) to quantify in a reliable manner the assessment and data collection process. The data is then used to automatically compute quantitative actions (typically expressed in instruction effort) that are to be implemented during classroom instruction and aim to minimize the difference between assessed outcomes and target outcomes. The difficulties in 
this process lie in several distinct planes. One is the definition of quantitative and precise metrics that reflect changes in the program. A second is the data collection and the action definitions that should minimize or, at least, allow the resolution of interdependencies and correlations among them. While these form an intellectually interesting modeling and feedback problem, one must also be prepared to accommodate some faculty resistance, indifference, or simply lack of time to perform such tasks. Viewing automation and consistency as a key for the success of continuous improvement, we have implemented this feedback process for the last four years and here we present some of our experiences.

\section{Introduction}

Objective and meaningful evaluation of student performance and career success is a complicated problem that sparks passionate conversations within the academic community. The basic issues lie in assessing the information content of data, their interpretation in terms of actions and the derivation of a quantitative model to connect it all. The complexity of the problem increases immensely when one is confronted with (large) statistical variations between action and results and the loss of sacred information about the individual when aggregating the data. When the associated actions reflect on the student's future career, as is the typical teacher grading problem, the translation of the student knowledge and performance into a single grade presents a modeling as well as an ethical challenge. On the other hand, when the action is to adjust the curriculum or the direction of a department, statistical modeling becomes more abstract and, perhaps, less controversial. This second type of problem is receiving considerably more attention among higher education departments since ABET has decreed that not only must the accredited schools demonstrate with data that they achieve their objectives, but they also implement consistent feedback actions based on the same data ${ }^{(1)(2)}$.

In the earlier ABET self study reports, the school collected and presented fairly standard data in the form of student reports, tests, and classroom materials, as well as some less standard data in the form of questionnaires and discussions with the school constituencies (faculty, students, alumni, industry). Then, looking at all the material for a long time, the author (or the evaluator) would try to find interesting correlations, or other indications to claim success or failure. Moreover, many of the questionnaires were assessing the degree of satisfaction of the students rather than an objective metric of success. Any corrective actions were also completely ad hoc and could (would) change between authors/evaluators, let alone the fact that any actions would have to be argued to exhaustion among faculty before a final vote.

Recently, the task of compiling the ABET self study report became a lot more complicated when the requirements included quantitative feedback from the assessment metrics, such as questionnaires and rubrics. ${ }^{(2)(3)}$ While this was certainly a step in the correct direction for an 
honest assessment of the school performance, it was also implicitly creating a new standard for data collection, interpretation, and reporting. At that point, our department decided to take a new, control-theoretic look at the ABET feedback process, aiming to develop an automated and consistent approach that was also palatable to the faculty and would minimize the time invested in data collection and processing, without sacrificing the integrity of the evaluation.

The principles and the details of our process are discussed in the following Sections. In a brief overview, a first-principles model is proposed, that views the student learning process as an information/knowledge propagation through a group of students, approximated by a mixing process. (While "guesstimating” some values for the model parameters provides a ballpark estimate of the response characteristics of the system, the main interest at this point is in the general system structure, inducing a controller structure for the feedback rules and algorithms.) This basic component of the student learning process is then augmented by a sampling process in the form of tests or rubric evaluations performed by the instructor and by an evaluation of the program objectives. It is also augmented by a process representing instruction effort to yield the control-theoretic model. For this model, the two-loop ABET feedback takes the standard form of a cascade controller structure where the inner loop controls metrics associated with the student knowledge or skills (program outcomes), and the outer loop is associated with the evaluation of the program objectives. For such a model, the basic structural connections and the selection of input-output signals were determined as a first pass after deliberations among the Undergraduate Committee members, composed of representatives of all the main EE sub-areas. However, there is an expectation that this choice of parameters will be refined with the data collected after the first few years of the program implementation.

In this fashion, the difficult tasks of accurately measuring student knowledge and mapping it to outcomes and objectives are circumvented. It is in fact the feedback that implicitly identifies the corresponding maps, with the entire process driven by the program objectives. The key assumptions that enable the design of such a controller are that the direction of change of the measured signals given a change in the control signals is known, and that the input-output maps are approximately decoupled. These assumptions are not automatically satisfied but they are intuitively expected to hold with judicious choice of the input-output signals, and a reasonable selection of the level of approximation of the system model.

Other topics that generate an interesting discussion, for educators that wish to implement a similar evaluation and feedback strategy, are the reaction and acceptance by the faculty and the students of the data collection and feedback action processes. 


\section{Modeling Principles: From Teaching Curriculum to Career Success}

The EE program has followed a common two-loop process diagram from ABET (see Figure 1) with regards to establishing, evaluating, and modifying both program and educational objectives and outcomes. It is envisioned that the left loop (program objective assessment) will see a complete cycle every 2 years, whereas a complete cycle of the right loop (program outcome assessment) will be achieved on an annual basis.

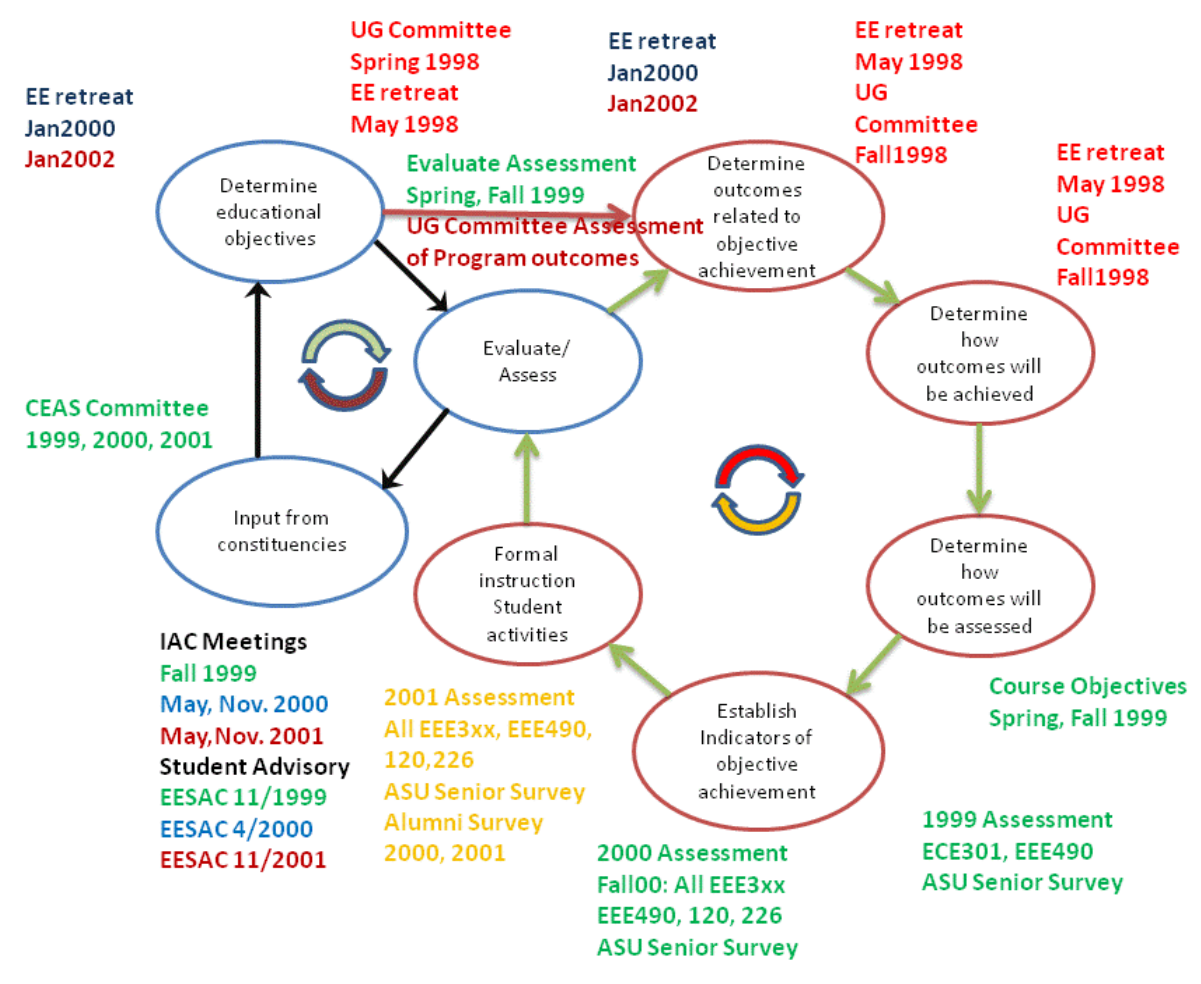

Figure 1. The ABET two-loop assessment and continuous improvement process

To be more specific, the EE Program Objectives are defined as expectations from our alumni, that three to seven years after graduation they exhibit one or more of the following:

1. Graduating from a graduate or professional school degree program

2. Achieving success in a government, industrial, commercial, entrepreneurial or academic position as evidenced by continued employment and technical accomplishments

3. Progressing in chosen career as shown by promotion to a position of increased technical, supervisory or management responsibility

The assessment and evaluation of the Program Objectives occur less frequently and involve "manual labor" in the sense that through a sequence of meetings and consulting with all the 
parties with interest in the EE Program, the Chair and the faculty make structural decisions on the program (e.g., new courses, specialization areas). At the same time, the Chair and the faculty (typically through the Undergraduate Committee) make decisions on the desired target levels of performance for the Program Outcomes. This part of the ABET assessment and continuous improvement is discussed next.

Consistent with ABET's definition ${ }^{(1)}$, the EE Program Outcomes are narrower statements that describe what students are expected to know and be able to do by the time of graduation:
a. ability to apply knowledge of mathematics, science, and engineering
b. ability to design and conduct experiments
c. ability to design a system, component, or process to meet desired needs
d. ability to function on multidisciplinary teams
e. ability to identify, formulate, and solve engineering problems
f. understanding of professional and ethical responsibility
g. ability to communicate effectively
h. broad education necessary to understand the impact of engineering solutions in global and societal context
i. recognition of the need for, and an ability to engage in life-long learning
j. knowledge of contemporary issues
k. ability to use the techniques, skills, and modern engineering tools necessary for engineering practice

It should be noted that within these outcomes there is a provision for the different EE subdisciplines to apply their own specific metrics to assess knowledge of math, science, etc. Each of the sub-disciplines, Systems (Communications, Signal Processing, Controls) Computer Engineering, Electromagnetics, Electronic Circuits, Power and Energy Systems, Solid-State Electronics, is responsible for maintaining these metrics at acceptable levels. To enable such a resolution, was divided "Outcome 3a” into 3 distinct parts, for Math, Science, and Engineering. Similarly, "Outcome 3b” was divided into 2 parts, (design and conduct experiments, analysis and interpretation of data) and "Outcome 3c" was divided into 3 parts (design of a: system, component, process).

Figure 1 is representative of the procedural (or programming) point of view but it does little to reveal causal relationships or control theoretic model properties. For an alternative input-output (or functional) model, depicted in Figure 2, we view the educational process affecting a group of students (e.g., ECEE majors) who receive education by the instructors. Education is of course an extremely complicated process and there are many external factors that influence it. Nevertheless, from our feedback perspective we can only manipulate the depth or emphasis of 
the instruction or perform structural changes to the curriculum. We focus on the former, which represents the fine adjustments that a program can implement to maintain its level of outcomes. We consider any structural changes as infrequent events where entire segments of the curriculum are modified, and courses are eliminated or introduced. Such changes are the viewed as discrete decisions made by a program committee (the faculty Undergraduate Committee in our case) whenever the fine adjustments are proven ineffective or the Program Objectives are modified.

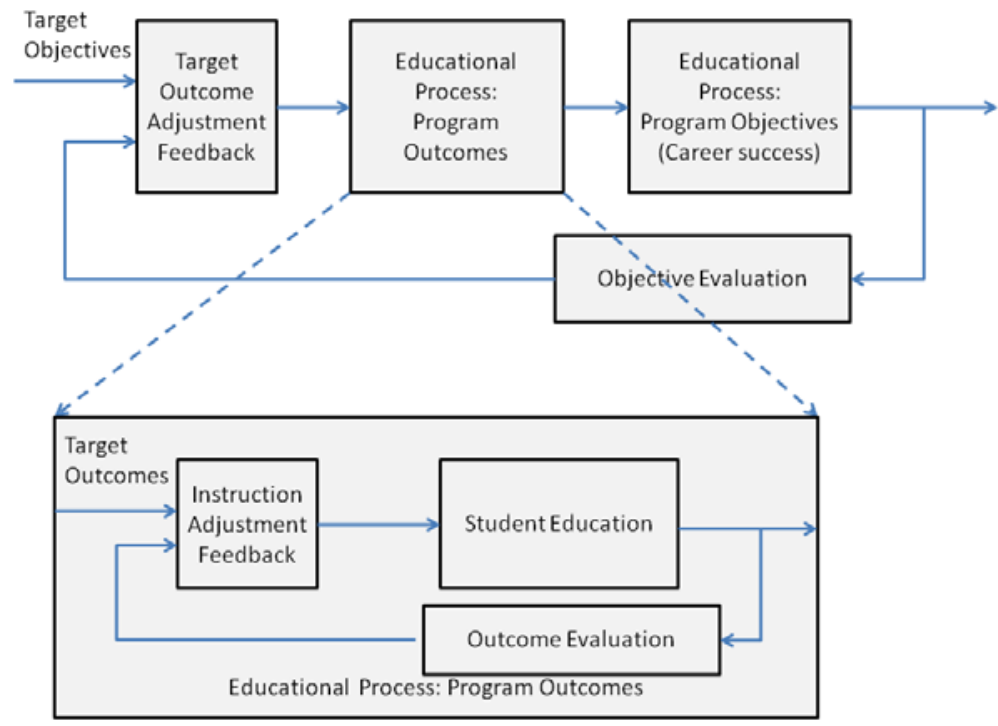

Figure 2. Block diagram representation of the ABET assessment and continuous improvement process

The adjustments in the instruction have an effect on the student education, a measure of which is obtained by an outcome evaluation process. While there are several acceptable methods to achieve such an evaluation, our decision was to implement a process that is consistent and simple and such that the any deviation from the target outcomes has a straightforward translation into a corresponding action. For example, if the student performance drops in Systems math, then the corresponding instruction effort in Signals and Systems should be increased. In other words, we assume that we know at least the direction of the required modification in instruction to achieve a certain change in the measured outcome. This change in the outcome also reflects a corresponding change in the overall educational qualities and the career success of the students. This assumption is only important because at first, we lack enough data, and do not possess good first principles models. It is not necessarily a restrictive assumption provided that we can compromise with a low resolution model and we select the outcomes and the actions carefully.

The next aspect of the model to be defined is the outcome evaluation process. Here we assume that each semester or year, a sample of the EE student population is polled for the skills defined 
in the Program Outcomes. This is achieved by administering relatively simple standard quizzes in a carefully selected set of courses that provide representative information on the skills of the student population. The important issues in this evaluation are:

1. The courses should be critical prerequisites and key senior courses that are typically attended by most students.

2. The test should be on background material or essential knowledge and should count at least a small percentage towards the final grade so that the students' effort is honest and consistent.

3. For any outcomes that are difficult or inconvenient to evaluate with a quiz, the instructor or the teaching assistants perform a rubric assessment of the skill for each student.

To reduce the time-lag between the testing of the skills and the application of the feedback actions we consider the student education process as being achieved in lower and upper division courses (roughly a junior-senior division) which can be sampled twice, at the senior year (in key technical electives) and at the junior-sophomore year. Since any changes in the latter will affect the outcomes in both the modeling of this system can also be viewed as a cascade of two education sub-processes.

Finally, an aggregate mathematical representation of this model can be derived by considering a loosely defined variable $x(k)$ representing a skill or knowledge at the time instant $\mathrm{k}$ for the undergraduate class. Here, since this is a first modeling effort and very few supporting data are available, we concentrate on average properties of the student population. We do recognize the importance of variance and distribution properties of such skills but any attempt to affect these in a predictable way requires much more detailed models (albeit with similar tools) and is deferred for the future. Now, a simple balance of this skill after a semester of study yields a change that depends on a fraction of students, say $\alpha$, attending a course which improves that skill by $u(k)$, a quantity that is manipulated by the emphasis and effort of instruction. At the same time, a fraction $\beta$ of students graduates and is replaced by new incoming students with a baseline level of the skill $x_{o}$. Performing the balance of the skill $x(k)$ and assuming "perfect mixing", we arrive at the fundamental model

$$
x(k+1)=(1-\alpha-\beta) x(k)+\alpha[x(k)+u(k)]+\beta x_{o}
$$

In the outcome assessment we obtain an estimate of this skill level, which for simplicity, we assume it is simply the same as the skill $\mathrm{x}$. It is now straightforward to extrapolate the same procedure to the other measured Program Outcomes and make some key observations on the structural properties of this model. 
1. The complete model has the form of a linear state space model with an external input (manipulated variable) and a bias term. There is a great volume of knowledge available for dynamical systems of this form. ${ }^{(4)}$

2. The parameters $\alpha, \beta$ can be estimated from enrollment statistics and can vary with time, but we anticipate that ballpark figures, (e.g., 0.1 ) should be adequate for a preliminary investigation. Alternatively, one could use the structure of the fundamental model and data (once they become available) to estimate the unknown parameters. ${ }^{(5)}$ Such an approach would have advantages in estimating additional effects, e.g., from the "forgetting" or "loss" of a skill.

3. The key assumption for this model is on the coupling between the various skills/outcomes. Independent or relatively decoupled models for the individual skills allow for the utilization of simple feedback algorithms that can be tuned in a fairly straightforward manner. On the other hand the existence of strong interactions between skills and/or actions brings in fully multivariable models where controller tuning is much more complicated. In fact, "arbitrary" or "high-gain" feedback may destabilize the system and a true quantitative tuning procedure must be used based on carefully derived quantitative models.

At this point, we should remark on our last observation and its implication on the flood of the many long questionnaires and surveys that appear in our collective efforts to improve our understanding and performance of the education process. Unless we know what this information means and how to act on it, it remains (and must remain) a statistical curiosity. In this situation, being "data rich but information poor" becomes a real risk. And this is exactly the reason behind our specific choices of outcomes, their assessment methodology and the corresponding actions. In the next section, we discuss the principles behind the derivation of the feedback policies and their implementation in terms of a fairly automated process.

\section{Feedback Control: Relaxing the accuracy requirements on the system model}

The application of feedback corrections in the education process, as in any control system, has as objective to reduce the system variability due to exogenous factors (disturbances) and model uncertainty. ${ }^{(6)}$ Control theory offers systematic tools to design controllers for systems in various mathematical formulations and with a various control objectives. A part of the controller design process is to correctly assess the limitations of the model and tailor the performance expectations accordingly. For our problem, one can interpret the application of feedback as the ability of using imperfect models to achieve an objective at the expense of a slower response.

At this stage, our expectation is to design and implement the entire feedback control process, even with very simplistic models and controllers. Having discussed the fundamental structure of 
the model and justified a completely decoupled first-cut feedback controller, we now turn our attention to the structure of such a feedback controller.

Each of the program outcomes represents skills and knowledge that are obtained in a several courses. For example, the ability to answer a question on Fourier transforms can be interpreted as analytical math skills which are the subject of several courses in the EE curriculum and they are also dependent on the EE sub-discipline. Instead of trying to isolate the effect of instruction in specific courses, we adopt the simplification that to improve a deficiency in the Systems-related math skills of the student population, we will increase the level of instruction (emphasis/effort) in all courses with that content. This simplifying principle not only reduces the dimensionality of the problem, but creates a set of actions that directly corresponds to the measured outcomes. This correspondence was defined through a series of deliberations by the Undergraduate Committee in the form of a matrix, referred to as the Assessment Feedback Matrix.

\begin{tabular}{|c|c|c|c|c|c|c|c|c|c|c|}
\hline \multirow[b]{2}{*}{341} & \multirow[b]{2}{*}{304} & \multicolumn{2}{|c|}{$<===$ TEST COURSES } & \multirow[t]{2}{*}{ PERFORMANCE CRITERION } & \multicolumn{3}{|c|}{ FEEDBACK COURSES $===>$} & \multirow[b]{2}{*}{335} & \multirow[b]{2}{*}{341} & \multirow[b]{2}{*}{352} \\
\hline & & 120 & 101 & & 101 & 120 & 304 & & & \\
\hline $341 \mathrm{a} 1$ & 304a1 & & & 3a-Math & & & $\begin{array}{l}304 \mathrm{a} 1, \\
480 \mathrm{a} 1, \\
455 \mathrm{a} 1, \\
407 \mathrm{a} 1\end{array}$ & 433a1 & $\begin{array}{l}\begin{array}{l}341 \mathrm{a} 1, \\
445 \mathrm{a} 1\end{array}\end{array}$ & 352a1 \\
\hline $341 \mathrm{a} 2$ & & & $101 \mathrm{a} 2$ & 3a-Science & $101 \mathrm{a} 2$ & & & & $341 \mathrm{a} 2$ & $\begin{array}{l}352 \mathrm{aa} 2, \\
435 \mathrm{a} 2, \\
436 \mathrm{a} 2\end{array}$ \\
\hline \multirow[t]{2}{*}{$341 \mathrm{a} 3$} & $304 \mathrm{a}^{3}$ & $120 \mathrm{a} 3$ & $101 \mathrm{a} 3$ & 3a-Engineering & $\begin{array}{l}101 \mathrm{a3}, \\
489 \mathrm{a} 3 \\
\end{array}$ & $120 \mathrm{a} 3$ & $\begin{array}{l}304 \mathrm{a} 3, \\
480 \mathrm{a} 3, \\
455 \mathrm{a} 3, \\
407 \mathrm{a} 3\end{array}$ & & $\begin{array}{r}341 \mathrm{a} 3, \\
445 \mathrm{a} 3 \\
\end{array}$ & \\
\hline & & $120 \mathrm{~b} 1$ & 101b1 & 3b - Design Conduct Experiments & $\begin{array}{l}\text { 101b1, } \\
489 \mathrm{~b} 1\end{array}$ & $120 \mathrm{~b} 1$ & & & & \\
\hline \multirow[t]{10}{*}{$341 \mathrm{~b} 2$} & & $120 \mathrm{~b} 2$ & $101 \mathrm{~b} 2$ & $\begin{array}{c}\text { 3b - Analyze Interpret data } \\
\text { Experiments }\end{array}$ & $\begin{array}{l}10162, \\
489 \mathrm{~b} 2\end{array}$ & $120 \mathrm{~b} 2$ & & & $341 \mathrm{~b} 2$ & \\
\hline & & $\frac{120 \mathrm{c} 1}{120 \mathrm{c} 2}$ & & $\begin{array}{l}\text { 3c-Design System } \\
\text { 3c-Design Component }\end{array}$ & & $\frac{12001}{1200^{2}}$ & & & & \\
\hline & & & & $\frac{3 c \text {-Design Component }}{3 \mathrm{c} \text { - Design Process }}$ & & & & & & \\
\hline & & $120 \mathrm{~d}$ & 101d & 3d-Multidisciplinary Teams & 101d & $120 \mathrm{~d}$ & & & & \\
\hline & $304 \mathrm{e}$ & & 101e & $\begin{array}{l}\text { 3e - Identify, formulate, solve } \\
\text { Engineering problems }\end{array}$ & $101 \mathrm{e}, 489 \mathrm{e}$ & & $\begin{array}{c}\text { 304e, } 455 \mathrm{e}, \\
407 \mathrm{e}, 480 \mathrm{k}, \\
489 \mathrm{e}\end{array}$ & $433 \mathrm{e}, 489 \mathrm{e}$ & & \\
\hline & & & $101 f$ & $\begin{array}{l}\text { 3f- Professional Ethical } \\
\text { Responsibility }\end{array}$ & 1017, 489f & & & & & \\
\hline & & $120 \mathrm{~g}$ & $101 \mathrm{~g}$ & 3g-Communicate Effectively & $101 \mathrm{~g}, 489 \mathrm{~g}$ & $120 \mathrm{~g}$ & & & & \\
\hline & & & 101h & $\begin{array}{l}\text { 3h - broad education engineering } \\
\text { impact in global and societal context }\end{array}$ & $101 \mathrm{~h}, 489 \mathrm{~h}$ & & & & & \\
\hline & & & & \begin{tabular}{|c|}
$3 i$ - Life-long learning \\
\end{tabular} & & & & & & $352 i, 436 i$ \\
\hline & & & & 3j-Contemporary Issues & & & & & & \\
\hline $341 \mathrm{k}$ & $304 \mathrm{k}$ & $120 \mathrm{k}$ & $101 \mathrm{k}$ & $3 \mathrm{k}$ - Modern Engineering Tools & $101 \mathrm{k}$ & $120 \mathrm{k}$ & $\begin{array}{l}304 \mathrm{k}, 480 \mathrm{k}, \\
455 \mathrm{k}, 407 \mathrm{k} \text {, } \\
489 \mathrm{k}\end{array}$ & $489 \mathrm{k}$ & $\begin{array}{l}341 \mathrm{k}, 445 \mathrm{k}, \\
489 \mathrm{k}\end{array}$ & \\
\hline & & & & & & & & & & \\
\hline
\end{tabular}

Figure 3. Detail of the Assessment Feedback Matrix: Courses on the left are where outcome assessment occurs. Courses on the right indicate actions that are influenced by the respective outcome assessments. 
A detail of this matrix is shown in Figure 3, containing the outcome assessment courses on the left and the action courses (all EE courses) on the right. In the assessment courses, the Program Outcomes a-k are tested and data are collected. While these tests or assessments are not strictly related to the course content, the courses are selected because they are attended by students with interest in that subject or sub-discipline. For example, EEE304 (Signals and Systems II) is a course that all Systems students take and are at a level to assess the following EE Program outcomes: a-Math skills, a-Engineering skills, e-Solving engineering problems, k-Modern tools.

On the right-hand side the EE Program courses are listed, with the influence that they receive in terms of feedback corrections. Each of these actions corresponds to portions of the EE Program Outcomes to which this course contributes. Moreover, each of these actions is driven by data obtained in one or more of the test courses. For example, even though this is not strictly necessary, EEE304 also contributes to the same Program Outcomes mentioned before (a,e,k). Any actions on the teaching efforts along these lines is driven by the corresponding data (a,e,k) collected in the related Systems courses EEE304 (self feedback), and form EEE 480 (Feedback Control), EEE407 (Digital Signal Processing), EEE455 (Communication Systems) and from the compulsory EEE 488, Senior Design (outer-loop control). At this point, and in the interest of simplicity, all the corrections computed from different sources are considered equivalent and are simply averaged.

Lastly, for the computational algorithm used to perform the quantitative estimates of corrections applied to the level instruction for each course, $(u(k+1)-u(k)$ in our previous notation of model (1)), we use the so-called Proportional-Integral (PI) compensator which is suitable for first order dynamical models with uncertain parameters and unknown bias. ${ }^{(7)}$ The update equations for this compensator are (in incremental form)

$$
P I: u(k+1)-u(k)=K_{p}(e(k+1)-e(k))+K_{i} e(k)
$$

where, $K_{p}, K_{i}$ are the tunable parameters of the PI compensator, usually referred to the proportional and integral gains. For the tuning of these parameters we use standard control theory and define our objective in terms of the bandwidth of the closed-loop system. ${ }^{(6)}$ For example, for a system model with parameters $\alpha=\beta=0.1$, and avoiding very aggressive corrections at this point, the compensator with parameters $K_{p}=2, K_{i}=0.4$ yields a reasonable response. That is, while the open loop settles sluggishly after a step change in about 30-40 periods (semesters), the feedback system rises to $90 \%$ of the steady state in 5 periods and settles in 20 periods. The only remaining ambiguity here is how to translate the computed correction in terms of instruction effort. We assume that this relationship is simply proportional and we use trial and error, several simulation studies and general insight about the physical system to obtain a first estimate of the proportionality constant. We do, however, plan to revisit this issue after we 
collect enough data for a quantitative validation of our model. The additional data will also allow us to revisit the control objective and perform further model refinements. ${ }^{(5)}$

In the next Section we present and briefly discuss the results from the application of this assessment and continuous improvement process ECEE.

\section{Implementation of the two-loop ABET process}

As previously discussed, the implementation of the EE continuous improvement process involves the following steps:

1. Review program objective assessment information. This is a high-level assessment performed at the External Advisory Board meetings, Faculty meetings and meetings with the graduating students. The chair and the Undergraduate Committee also take into account feedback from peer institutions and graduate programs.

2. Adjust levels of outcome targets. Using the results from Step 1, the Undergraduate Committee and the chair review the levels of outcome targets and revise them if a deficiency becomes apparent.

3. The outcome targets and the quantitative outcome assessment data are used to compute the recommendations of instruction effort adjustment for all undergraduate courses. After the end of the semester, the instructors notify the Undergraduate Committee on the actions taken based on the recommendations.

4. The Undergraduate Committee reviews the effort adjustment recommendations and, if reasonable, releases them for dissemination to the instructors. If the effort recommendations are not feasible (and this conditions persists), then the Undergraduate Committee, the chair, and ultimately the faculty decide on whether structural changes in the curriculum are necessary (e.g., introduction of a new course, or material redistribution), or whether the assessment instruments (test questions, rubrics) require modification.

Beyond the above regular process, other infrequent events may affect the continuous improvement process. For example, such events include the periodic ABET evaluation changes in the objectives or constraints imposed by higher-level entities, e.g., the School of Engineering or the University. While all aspects of the continuous improvement process are important, the one that is of interest here is Step 3, which also involves the more intensive and quantitative data processing.

The main observations from results obtained so far (Fall2007-Spring2010) are discussed in the following list. Representative data collected for the various courses are also shown in Figure 4 
and Figure 5. These figures show the variability in meeting the outcome targets. The summary of our observations is given below.

1. The data collected during the first 3 semesters were used to establish the data collection procedures and the baselines for all Program Outcomes. Initially, the development of the tests and the questionnaires was aimed to produce steady state scores around $70 \%$ to allow room for variation, but some adjustment of both targets and tests was necessary after the first data were collected.

2. The data are collected in 16 key courses to sample all possible sub-disciplines and specializations of Electrical Engineering, as well as to quantify intermediate performance with respect to the outcomes. The assessment involves a total of 89 distinct measurements and there are 16 outcomes assessed, which are the previously stated 11 outcomes a-k, except that three of them are further subdivided to increase resolution and have the ability for more precise feedback action. In each of the 16 key courses only a subset of the measurements is collected, as appropriate for the student skills that are sampled.

3. The average deviations per outcome fluctuated between $+/-10 \%$ in the Spring 2009 . The positive sign here indicates deficiency relative to the target and the negative sign indicates that the targets have been exceeded and there is potential of effort saving. The same deviations were $+10 \%-30 \%$ in the Fall 2010. The aggregate deviation data are illustrated in Figure 6 . The reduction of the average by about $-6 \%$ indicates that the continuous improvement process did improve the numbers. Whether that reflects better student education and more successful careers is much harder (and slower) to assess.

4. The feedback adjustments are computed in the form of coverage effort recommendations, expressed as \% effort, and communicated to each instructor. In total, there are 140 distinct actions represented by feedback entries in the various Undergraduate courses. Naturally, most of them correspond to Science and Engineering topics. The range of average actions per Outcome increased from [-2\%,6\%] in 2009 to [$10 \%, 10 \%]$ in 2010. The aggregate recommended feedback actions are illustrated in Figure 6 . The overall average dropped from $0.6 \%$ to $-0.6 \%$, implying that there were more recommendations to reduce (and redirect) the effort to Program Outcomes. If this trend continues, it will be very useful in identifying potential instruction reduction points that can then be redirected to curriculum update and modernization efforts that are not yet covered by the Program Outcomes.

5. The initial effort in automating the data processing does pay off in the sense that much of the process is automated and distributed to many faculty members. Even though there are often difficulties in reporting the data (lack of interest, busy schedules) the additional effort requested by each individual faculty is relatively small. This distributed data collection and reporting also implies, that no individual faculty is responsible for the 
entire very time consuming process. This increases the probability that the system is used consistently and without gaps, thus increasing its effectiveness.

\section{Conclusions}

The automated data processing and computation of corrective actions can greatly facilitate and provide consistency to the ABET continuous improvement process. The implementation of such a procedure should rely on a sound model to ensure that the feedback corrections are meaningful and will be adopted by the faculty. The quantitative analysis of the data can also reveal potential areas of curriculum improvement both in terms of strengthening deficiencies and removing redundancies. This part of the continuous improvement cannot be easily (if at all) automated, but the quantitative data that have become available can provide useful insight to the decisionmakers. Finally, the distribution of the data collection load and the automatic data processing ensures that no single faculty is burdened with the full load of the work and maximizes the probability that the process will be continued in the future. This is particularly important since our simple first-principles model confirms our intuitive expectation that the underlying learning and education process has long time constants and the effects of any changes will not become evident before the elapse of a considerable time period. During this time, the automated feedback mechanism can help to avoid the detrimental effects of human impatience or neglect and, thus, improve the chances for success of the continuous improvement policy. 


\section{Outcome Assessment 2007-2010}
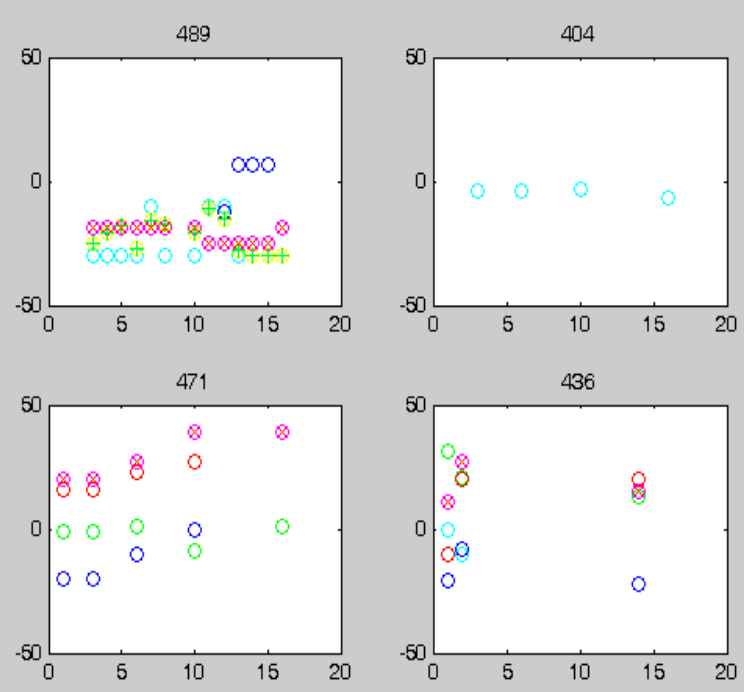

OUTCOMES

1. 3a- Math

2. 3a-Science

3. 3a-Engineering

4. 3b-Design Conduct Experiments

5. 3b-Analyze Interpret data Experiments

6. 3c-Design System

7. 3c-Design Component

8. $3 c$-Design Process

9. 3d-Multidisciplinary Teams

10. 3e-Identify, formulate, solve Engineering problems

11. $3 \mathrm{f}-$ Professional Ethical Responsibilities

12. $3 \mathrm{~g}$-Communicate Effectively

13. $3 \mathrm{~h}$ - broad education engineering impact in global and societal context

14. $3 \mathrm{i}$ - Life-long learning

15. $3 \mathrm{j}$ - Contemporary lssues

16. 3k-Modern Engineering Tools

\section{Outcome Assessment 2007-2010}

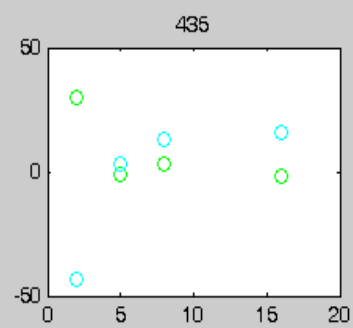

433

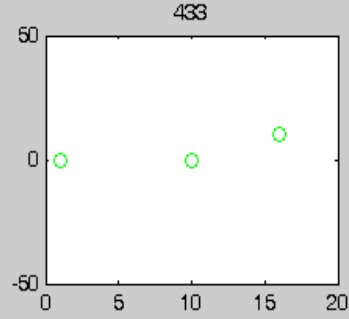

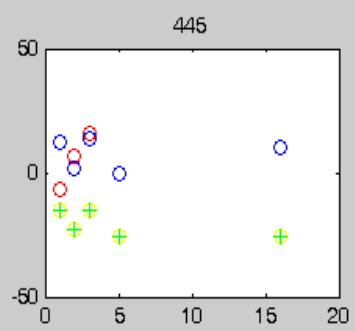

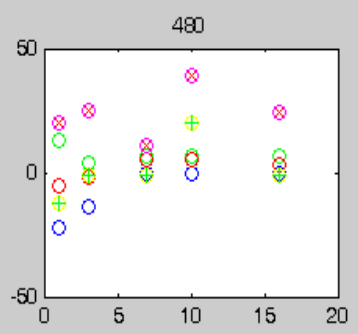

OUTCOMES

1. 3a-Math

2. 3a-Science

3. 3a-Engineering

4. $3 \mathrm{~b}-$ Design Conduct Experiments

5. $3 \mathrm{~b}$-Analyze Interpret data Experiments

6. 3c-Design System

7. 3c-Design Component

8. $3 c$ - Design Process

9. $3 \mathrm{~d}$-Multidisciplinary Teams

10. $3 \mathrm{e}$-Identify, formulate, solve Engineering problems

11. $3 f-$ Professional Ethical Responsibilities

12. $3 \mathrm{~g}$-Communicate Effectively

13. $3 \mathrm{~h}$ - broad education engineering impact in global and societal context

14. $3 \mathrm{i}$ - Life-long learning

15. 3j-Contemporary Issues

16. 3k-Modern Engineering Tools

Figure 4. Assessment of ECEE Program Outcomes for the various test courses. Positive values indicate deficiency. Data collection frequency is not uniform in all courses. Course numbers: 489-Senior Design Lab, 404-Real-Time DSP Systems, 471-Power System Analysis, 436-Fundamentals of Solid-State Devices, 435-Microelectronics, 445-Microwaves, 433-Analog Integrated Circuits, 480-Feedback Systems. 


\section{Outcome Assessment 2007-2010}
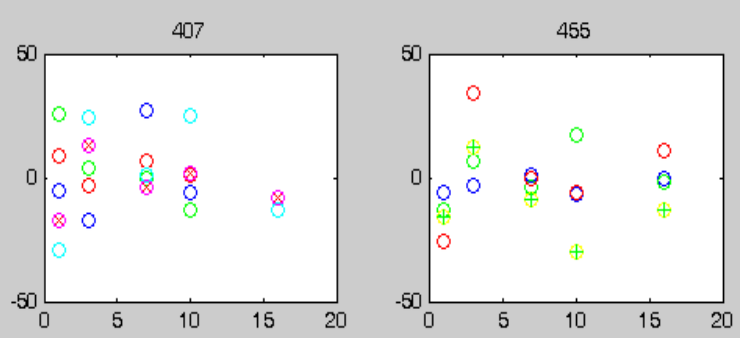

OUTCOMES

1. 3a-Math

2. 3a-Science

3. 3a-Engineering

4. 3b-Design Conduct Experiments

5. 3b-Analyze Interpret data Experiments

6. 3c-Design System

7. 3c-Design Component

8. $3 c$ - Design Process

9. 3d-Multidisciplinary Teams
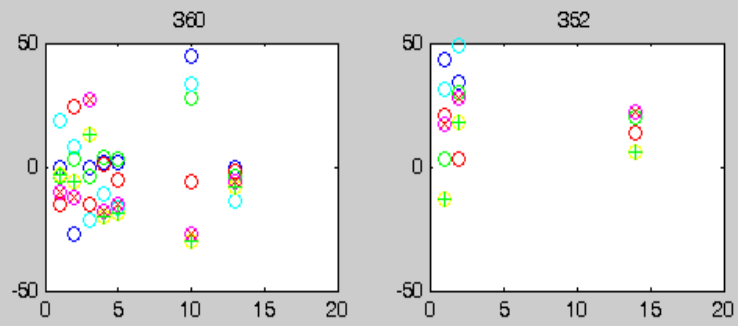

10. $3 e$-Identify, formulate, solve Engineering problems

11. $3 \mathrm{f}$-Professional Ethical Responsibilities

12. $3 \mathrm{~g}$ - Communicate Effectively

13. $3 \mathrm{~h}$ - broad education engineering impact in global and societal context

14. $3 i$ - Life-long learning

15. $3 \mathbf{j}$ - Contemporary lssues

16. 3k-Modern Engineering Tools

\section{Outcome Assessment 2007-2010}
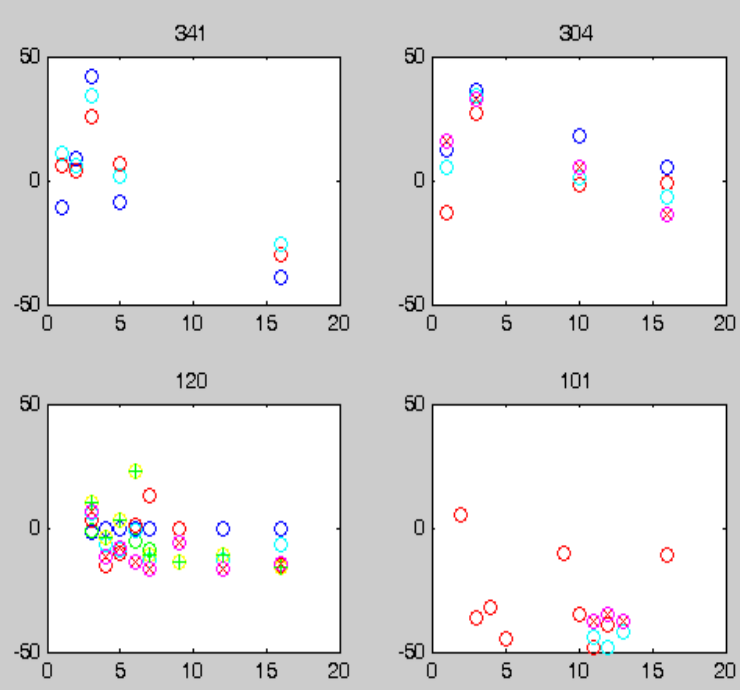

OUTCOMES

1. 3a-Math

2. 3a-Science

3. 3a-Engineering

4. 3b-Design Conduct Experiments

5. 3b-Analyze Interpret data Experiments

6. 3c-Design System

7. 3c-Design Component

8. 3c-Design Process

9. 3d-Multidisciplinary Teams

10. $3 e$-Identify, formulate, solve Engineering problems

11. $3 \mathrm{f}$-Professional Ethical Responsibilities

12. $3 \mathrm{~g}$ - Communicate Effectively

13. $3 \mathrm{~h}$ - broad education engineering impact in global and societal context

14. $3 \mathrm{i}$ - Life-long learning

15. $3 \mathbf{j}$ - Contemporary lssues

16. 3k-Modern Engineering Tools

Figure 5. Assessment of ECEE Program Outcomes for the various test courses. Positive values indicate deficiency. Data collection frequency is not uniform in all courses. Course numbers: 407-Digital Signal Processing, 455-Communication Systems, 360-Energy Systems and Power Electronics, 352-Properties of Electronic Materials, 341-Electromagnetic Fields and Waves, 304-Signals and Systems II, 120-Digital Design Fundamentals, 101-Introductin to Engineering Design. 


\section{ABET Data Visualization}

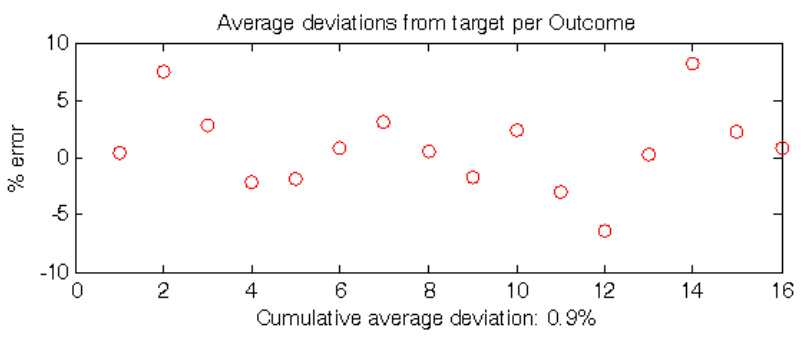

Spring 2009

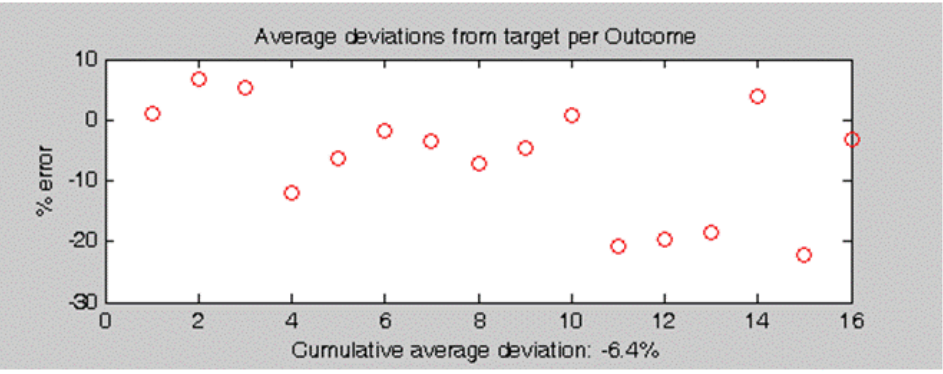

Fall 2010

\section{ABET Feedback Visualization}

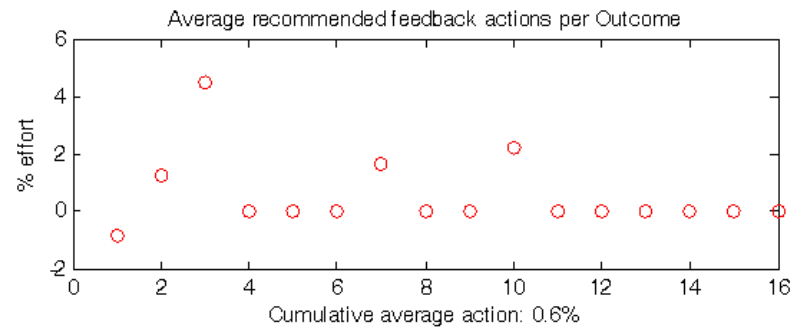

Spring 2009

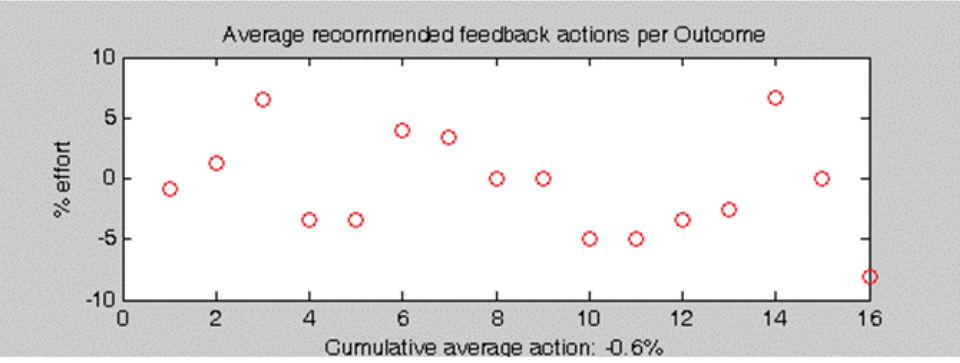

Fall 2010

Figure 6. Top: Visualization of the ABET data for the 16 outcomes, averaged over all 16 data-collection courses. Bottom: Visualization of the recommended ABET feedback actions corresponding to the 16 outcomes, averaged over all EE courses. 


\section{Bibliography}

1. ABET. Criteria for Accrediting Engineering Programs: Effective for Evaluations During the 2009-2010 Accrditation Cycle. Baltimore MD : ABET Inc., Nov. 1, 2008.

2. Rogers, G. Faculty Worksop on Assessing Program Outcomes . s.l. : ABET Inc., 2007.

3. Andrade, Heidi Goodrich. Understanding Rubrics [Online]. s.l. :

<http://www.middleweb.com/rubricsHG.html>, 22 October 2001.

4. Kailath, T. Linear Systems. Englewood Cliffs : Prentice Hall, 1980.

5. Ljung, L. System Identification. Englewood Cliffs : Prentice Hall, 1987.

6. John Doyle, Bruce Francis, Allen Tannenbaum. Feedback Control Theory. s.l. : Macmillan Publishing Co., 1990.

7. Hagglund, K. Astrom and T. PID Controllers: Theory, Design and Tuning. 2nd Edition. Research Triangle Park, NC : Instrument Society of America, 1995. 